\title{
Bezafibrate for the treatment of dyslipidemia in patients with coronary artery disease: 20-year mortality follow-up of the BIP randomized control trial
}

\author{
Yaron Arbel ${ }^{1 *+} \mathbb{D}$, Robert Klempfner ${ }^{2,4+}$, Aharon Erez ${ }^{2}$, Ilan Goldenberg ${ }^{2,4,5}$, Sagit Benzekry ${ }^{2}$, Nir Shlomo ,
} Enrique Z. Fisman ${ }^{3}$, Alexander Tenenbaum ${ }^{3}$ and for the BIP Study Group

\begin{abstract}
Background: Recent data support the renewed interest in hypertriglyceridemia as a possible important therapeutic target for cardiovascular risk reduction. This study was designed to address the question of all-cause mortality during extended follow-up of the BIP trial in patients stratified by baseline triglyceride levels.

Methods: In the BIP trial 3090 patients with proven coronary artery disease were randomized to bezafibrate $400 \mathrm{mg} /$ day or placebo. All-cause mortality data after 20 years of follow-up, were obtained from the National Israeli Population Registry. Patients with hypertriglyceridemia (triglycerides $\geq 200 \mathrm{mg} / \mathrm{dL}, \mathrm{n}=458$ ) were equally distributed among the study groups (15\% in both placebo and bezafibrate groups).

Results: During follow-up 1869 patients died (952 in placebo vs. 917 in bezafibrate group). Following multivariate adjustment allocation to bezafibrate was associated with small but significant $10 \%$ mortality risk reduction (HR 0.90; $95 \% \mathrm{Cl} 0.82-0.98, \mathrm{p}=0.026$ ). Variables associated with significantly increased mortality risk were history of a past MI, NYHA class, diabetes, age, higher BMI and glucose level. In patients with hypertriglyceridemia multivariate analysis demonstrated a $25 \%$ all-cause mortality risk reduction associated with allocation to bezafibrate (HR 0.75, Cl $95 \%$ $0.60-0.94 ; p=0.012$ ). In patients without hypertriglyceridemia bezafibrate had no significant effect on long-term mortality.
\end{abstract}

Conclusions: During long-term follow-up bezafibrate-allocated patients experienced a modest but significant $10 \%$ reduction in the adjusted risk of mortality. This effect of bezafibrate was more prominent among patients with baseline hypertriglyceridemia ( $25 \%$ mortality risk reduction).

Keywords: Bezafibrate, Triglycerides, Coronary disease, Prognosis, Mortality, Lipids, Cholesterol, HDL

\section{Background}

There is a growing body of recently published genetic and epidemiological evidences which demonstrated a causal role of triglycerides (TG) and TG-rich lipoproteins in the pathogenesis of atherosclerosis and particularly

\footnotetext{
*Correspondence: yaronarbel@gmail.com

${ }^{\dagger}$ Yaron Arbel and Robert Klempfner contributed equally to this work ${ }^{1}$ Department of Cardiology, Tel Aviv Medical Center, Affiliated to the Sackler Faculty of Medicine, Tel Aviv University, Tel Aviv, Israel

Full list of author information is available at the end of the article
}

coronary artery disease (CAD) [1-5]. These data support the renewed interest in hypertriglyceridemia as a possible important therapeutic target for cardiovascular risk reduction [6-8]. Historically, one of the main aims of the Bezafibrate Infarction Prevention (BIP) trial was to assess the effect of reducing TG levels (alongside with rising of HDL-C levels) on cardiac risk in patients with established CAD [9]. During the course of the study, TG levels were reduced by $21 \%$ and HDL-C increased by $18 \%$ among patients that had received bezafibrate. Nevertheless, 
despite these favorable lipid-modifying effects, bezafibrate therapy was associated with only a non-significant trend of a reduction of the incidence of primary end point (fatal or non-fatal myocardial infarction or sudden death). However, a significant $39.5 \%$ reduction in the primary end point in patients with high baseline TG ( $\geq 200 \mathrm{mg} / \mathrm{dl}$ ) was observed. Also during post hoc analysis of the BIP trial we have shown that bezafibrate significantly reduced the incidence of myocardial infarction in patients with the metabolic syndrome [10]. The relatively short mean follow-up of 6.2 year which could be achieved during the double-blind phase of the BIP trial precluded a determination of whether bezafibrate affected total mortality. We hypothesized that early favorable effects of bezafibrate on lipids and myocardial infarction during the original trial period could be translated in a subsequent reduction in total mortality during a longer-term observation. Therefore, this study was designed to address the question of mortality during extended 20-year follow-up of the BIP trial.

\section{Methods}

The BIP trial

The BIP trial evaluated the effect of bezafibrate versus placebo on major coronary events and mortality in CHD patients. Details of the study design have been previously published [9, 11-13]. Briefly, 3090 male and female patients 45-74 years of age with a history of MI and/or stable angina pectoris and a lipid profile of serum total cholesterol between 180 and $250 \mathrm{mg} / \mathrm{dL}$, low-density lipoprotein cholesterol (LDL-C) $\leq 180 \mathrm{mg} / \mathrm{dL}(\leq 160 \mathrm{mg} / \mathrm{dL}$ for patients $<50$ years), HDL-C $\leq 45 \mathrm{mg} / \mathrm{dl}$, and triglycerides $\leq 300 \mathrm{mg} / \mathrm{dL}$ were randomized to bezafibrate $400 \mathrm{mg} /$ day or placebo between May 1990 and January 1993 and followed up over a mean period of 6.2 years (median 6.2 years; interquartile range [IQR] 5.3-6.8 years).

Stable angina pectoris confirmed by coronary angiography, and/or radio- nuclear studies or standard exercise tests. The main exclusion criteria were insulin-dependent diabetes mellitus, severe heart failure, unstable angina pectoris, hepatic or renal failure, known sensitivity to bezafibrate, or current use of lipid-modifying drugs.

After discontinuation of the study medication, patients were observed for coronary events for an additional period, bringing the total follow-up time to a mean of 8.2 years (median 7.9 years; interquartile range $7.2-$ 8.7 years). This study reports all-cause mortality data obtained in 2014 from the National Israeli Population Registry presenting 20 years follow-up [IQR 12-22.6]. The identification number recorded during enrollment was matched to mortality data stored at the national register and verified by matching date of birth. The current analysis is based on over 52,100 patient-years data.

\section{Study population}

In the present analysis we included all the subjects included in the original BIP randomized study with the exception of 19 subjects that did not take any study medication. Excluded patients were equally distributed between the Bezafibrate and placebo arm (9 and 10 patients, respectively). IRB approval was obtained both for the original study and for the current long term follow-up data acquisition.

\section{Statistical analysis}

Variables were expressed as mean $\pm \mathrm{SD}$, and categorical data were summarized as percentages. Baseline characteristics of patients with patients with $\mathrm{TG} \geq 200 \mathrm{mg} / \mathrm{dL}$ by the original treatment allocation group were compared using the Chi-square test for categorical parameters and Student $t$ test or Mann-Whitney for continuous variables, as appropriate. Similarly, we compared the pre-specified subgroups of subjects with baseline triglycerides levels $\geq 200 \mathrm{mg} / \mathrm{dL}$ to those with lower levels of triglycerides. The supplemental online data includes characteristics and comparison of the entire study population by original allocation to bezafibrate or placebo.

Survival curves were constructed by the Kaplan-Meier method, and the significance of the variation between them was assessed using a Log-rank test. We compared survival for the entire study population by original treatment allocation (placebo vs. bezafibrate), followed by survival analysis by treatment allocation in the pre-specified sub-groups of subject with TG $\geq 200 \mathrm{mg} / \mathrm{dL}$ and $<200 \mathrm{mg} / \mathrm{dL}$.

We used multivariate Cox proportional hazards regression modeling in order to explore the adjusted risk reduction associated with bezafibrate treatment in the entire study population and separately in the subgroup of patients with TG $\geq 200 \mathrm{mg} / \mathrm{dL}$. Covariates were selected if univariate association was significant $(\mathrm{p}<0.05)$ or clinical studies have demonstrated robust association with prognosis in previous studies. The following covariates were selected using the best subset method: age, gender, BMI, prior MI, history of diabetes mellitus, reported hypertension, NYHA functional class $\geq 2$, and baseline serum values of HDL and glucose. An additional multivariate model was constructed including lipid-lowering medication initiated during the BIP study or the extended follow-up period (total 8 years' duration) introduced as a time dependent covariate. Proportionality of hazard assumption was verified in all models.

We further undertook interaction term analysis in order to explore mortality associated with fibrate vs. placebo treatment by TG group (below $200 \mathrm{mg} / \mathrm{dL}$ vs. $\geq 200 \mathrm{mg} / \mathrm{dL}$ ) with the covariates described above.

All statistical tests were two-sided, and a $P$ value of less than 0.05 was considered to indicate statistical 
significance. The $\mathrm{P}$ values for interaction are reported. Analyses were carried out with the use of SPSS software, version 22 (IBM Inc.) and SAS, version 9.3.

\section{Results}

The present study included patients from the original BIP cohort: 1548 patients allocated to the bezafibrate group and 1542 patients allocated to the placebo group. Clinical characteristics, laboratory values, and medical therapy were similar in the 2 original study treatment groups (Additional file 1: Table A). Nearly $80 \%$ of the patients had a history of MI, and $10 \%$ had treated diabetes mellitus. Beta-blockers were prescribed to nearly $40 \%$ of study patients, calcium-channel blockers to $50 \%$, and angiotensin-converting enzyme inhibitors to $12 \%$.

Patients with triglycerides $\geq 200 \mathrm{mg} / \mathrm{dL}$ ( $\mathrm{n}=458$ ) were equally distributed among the 2 study groups $(15 \%$ in both placebo and bezafibrate groups). There was no significant difference in characteristics of patients with TG $\geq 200 \mathrm{mg} / \mathrm{dL}$ randomized to the placebo $(\mathrm{n}=224)$ vs. fibrate $(\mathrm{n}=234)$ treatment arm (Table 1$)$.

Compared to patients with TG $<200 \mathrm{mg} / \mathrm{dL}$ patients with baseline TG $\geq 200 \mathrm{mg} / \mathrm{dL}$ presented with similar clinical features, with the exception of a higher BMI and younger age. Laboratory values differed significantly, including lower HDL and lower LDL and higher fasting glucose levels (all $\mathrm{p}<0.001$; Additional file 2: Table B).

\section{Entire study population mortality}

During the follow-up period 1869 patients died (61\%), $952(62 \%)$ in the placebo group and $917(60 \%)$ in the bezafibrate group (Fig. 1). Following multivariate adjustment, allocation to the bezafibrate arm was associated with significant $10 \%$ mortality risk reduction (HR 0.90; $95 \%$ CI $0.82-0.98, \mathrm{p}=0.026$; Table 2). Variables associated with significantly increased mortality risk were

Table 1 Baseline Clinical and Laboratory characteristics of patients with baseline TG $\geq 200 \mathrm{mg} / \mathrm{dl}$ by original study allocation

\begin{tabular}{|c|c|c|c|}
\hline & Bezafibrate group $(n=234)$ & Placebo group $(n=224)$ & $P$ value \\
\hline \multicolumn{4}{|l|}{ Clinical characteristics } \\
\hline Age, years & $58 \pm 7$ & $58 \pm 7$ & 0.62 \\
\hline Male & $210(90)$ & $199(89)$ & 0.75 \\
\hline Hypertension & $78(33)$ & $80(36)$ & 0.61 \\
\hline DM & $28(12)$ & $21(9)$ & 0.37 \\
\hline $\mathrm{BMI}, \mathrm{kg} / \mathrm{m}^{2}$ & $28 \pm 4$ & $28 \pm 3$ & 0.81 \\
\hline NYHA functional class $\geq 2$ & $71(30)$ & $53(25)$ & 0.41 \\
\hline AP class $\geq 2$ & $72(30)$ & $53(23)$ & 0.40 \\
\hline Prior Ml & $173(74)$ & $171(76)$ & 0.60 \\
\hline COPD & $4(2)$ & $8(4)$ & 0.22 \\
\hline \multicolumn{4}{|l|}{ Medical therapy } \\
\hline Anti-platelets & $157(67)$ & $155(69)$ & 0.63 \\
\hline Beta-blockers & $116(49)$ & $94(42)$ & 0.10 \\
\hline Nitrates & $114(51)$ & $127(54)$ & 0.47 \\
\hline $\mathrm{Ca}^{2+}$-blockers & $107(46)$ & $116(52)$ & 0.11 \\
\hline ACE inhibitors & $30(13)$ & $27(12)$ & 0.80 \\
\hline Diuretics & $27(11)$ & $36(16)$ & 0.16 \\
\hline Non-study LLD & $136(58)$ & $122(54)$ & 0.40 \\
\hline \multicolumn{4}{|l|}{ Laboratory values } \\
\hline Glucose & $104 \pm 18$ & $103 \pm 19$ & 0.76 \\
\hline Total cholesterol & $215 \pm 18$ & $216 \pm 18$ & 0.46 \\
\hline HDL-C & $31 \pm 5$ & $32 \pm 5$ & 0.14 \\
\hline$L D L-C$ & $138 \pm 17$ & $140 \pm 17$ & 0.74 \\
\hline Triglycerides & $235 \pm 25$ & $235 \pm 29$ & 0.94 \\
\hline Fibrinogen & $361 \pm 74$ & $355 \pm 75$ & 0.37 \\
\hline
\end{tabular}

Values are presented as $\mathrm{n}(\%)$ or mean $\pm \mathrm{SD}$

$A P$ angina pectoris, $A C E$ angiotensin-converting enzyme, $B M I$ body mass index, $C O P D$ chronic obstructive pulmonary disease, $D M$ diabetes mellitus, $H D L-C$ highdensity lipoprotein cholesterol, LDL-C low-density lipoprotein cholesterol, LLD lipid-lowering drug, MI myocardial infarction, NYHA New York Heart Association 


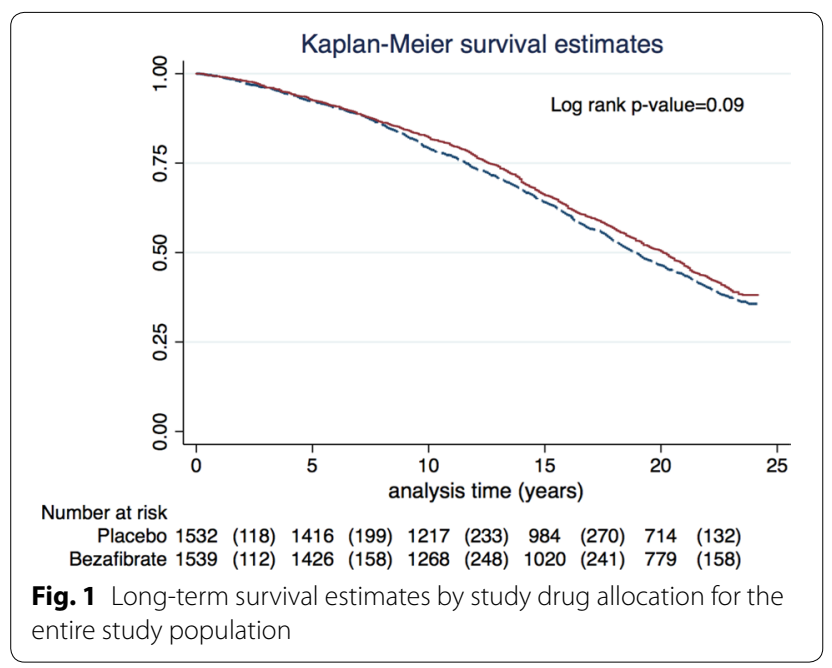

Table 2 Independent predictors of all-cause mortality at 20 years of the entire study cohort

\begin{tabular}{lllll}
\hline & HR & \multicolumn{2}{c}{$\mathbf{9 5} \% \mathbf{C l}$} & P value \\
\cline { 3 - 4 } & & Lower & Upper & \\
\hline Fibrate treatment & 0.90 & 0.82 & 0.98 & 0.026 \\
Past MI & 1.45 & 1.30 & 1.64 & $<0.001$ \\
Glucose (per 1 mg/dl) & 1.01 & 1.005 & 1.01 & $<0.001$ \\
Age (per year increment) & 1.09 & 1.08 & 1.10 & $<0.001$ \\
BMI (per unit) & 1.03 & 1.01 & 1.04 & $<0.001$ \\
NYHA functional class $\geq$ II & 1.13 & 1.04 & 1.22 & 0.005 \\
TG $\geq$ 200 mg/dl & 1.04 & 0.92 & 1.18 & 0.52 \\
Diabetes mellitus & 1.34 & 1.14 & 1.58 & $<0.001$ \\
\hline
\end{tabular}

Model further adjusted for hypertension, gender, baseline HDL and use of nonstudy lipid lowering medication as a time dependent covariate

history of a past MI (HR 1.45; CI 0.92-0.98), NYHA class >1 (HR 1.13; CI 1.04-1.22), diabetes (HR 1.34; CI 1.14-1.58), older age, higher BMI and glucose levels (all $\mathrm{p}<0.01$; Table 2).

\section{Mortality in TG sub-groups}

Next, we divided our cohort according to their baseline triglyceride levels by original study allocation. Patients with baseline triglycerides $\geq 200 \mathrm{mg} / \mathrm{dL}$ allocated to placebo $(\mathrm{n}=224)$ and bezafibrate groups $(\mathrm{n}=234)$ were compared. Patients that were treated with bezafibrate had a non-significant unadjusted survival benefit (57 vs. $62 \%$; Log rank p value $=0.14$ )

Multivariate analysis demonstrated a $25 \%$ adjusted all-cause mortality risk reduction in patients with hypertriglyceridemia treated by bezafibrate (HR 0.75; CI $95 \%$ $0.60-0.94 ; \mathrm{p}=0.012$; Fig. 2). Variables associated with significantly increased mortality risk in this subgroup were: age, past MI, use of non-study lipid lowering medication, and diabetes mellitus (Table 3 ).

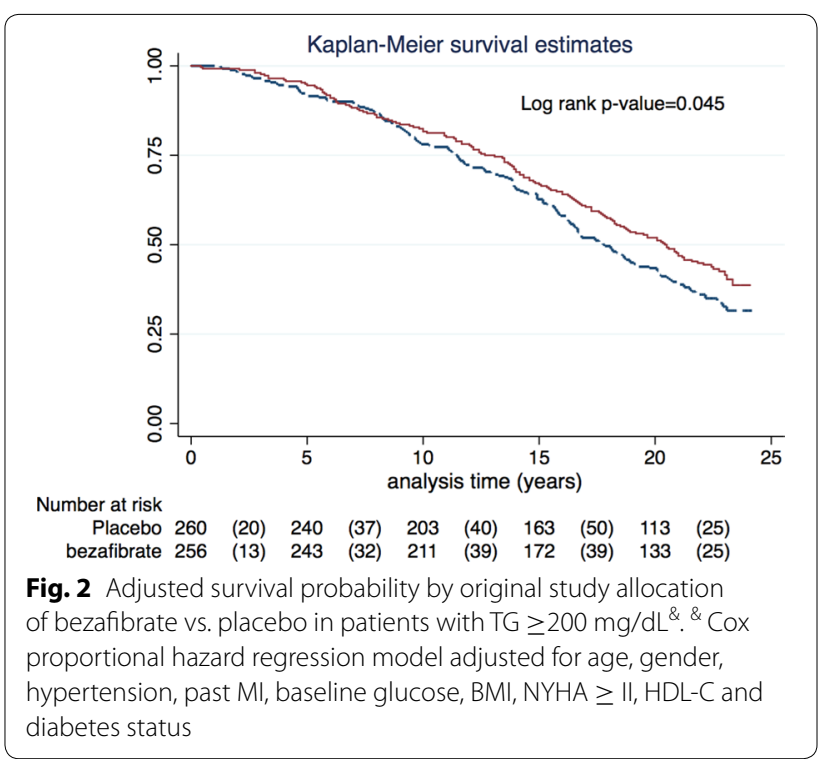

Table 3 Independent predictors of all-cause mortality at 20 years in the sub group with baseline TG $\geq 200 \mathrm{mg} / \mathrm{dL}$

\begin{tabular}{llllc}
\hline & HR & \multicolumn{2}{l}{$\mathbf{9 5} \% \mathbf{C l}$} & P value \\
\cline { 3 - 4 } & & Lower & Upper & \\
\hline Fibrate treatment & 0.75 & 0.60 & 0.94 & 0.012 \\
Past MI & 1.53 & 1.15 & 2.00 & 0.004 \\
Glucose & 1.00 & 0.99 & 1.01 & 0.12 \\
Age (per year increment) & 1.08 & 1.07 & 1.11 & $<0.001$ \\
BMI (per unit) & 1.01 & 0.98 & 1.05 & 0.39 \\
NYHA functional class $\geq \|$ & 1.09 & 0.89 & 1.33 & 0.41 \\
HDL-C (per 1 mg/dl) & 1.00 & 0.97 & 1.02 & 0.76 \\
Diabetes mellitus & 1.88 & 1.36 & 2.61 & $<0.001$ \\
\hline
\end{tabular}

Model further adjusted for hypertension, gender and non-study lipid lowering medication as a time dependent covariate (all $p>0.05$ )

Interaction term analysis demonstrated that the adjusted risk reduction associated with fibrate treatment compared to placebo is associated with a $21 \%$ risk reduction (HR 0.79; CI 0.63-0.98; $\mathrm{p}=0.03$ ) in subjects with elevated TG whereas this effect was not significant in the group with lower TG values ( $\mathrm{p}$ for interaction $=0.11$; Fig. 3).

\section{Discussion}

There are two main findings in this long-term study which based on the intention-to-treat principle with more than 52,000 person-years of follow-up. First, patients treated during original BIP trial period by bezafibrate experienced a modest but significant $10 \%$ reduction in the adjusted risk of mortality compared with patients allocated to the original placebo group. Second, the long-term benefit of bezafibrate was more prominent 


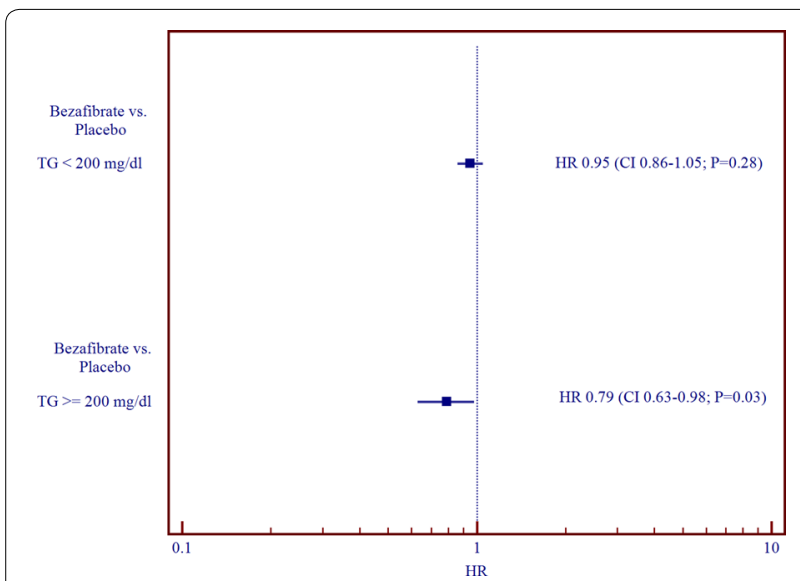

Fig. 3 Independent effect of the adjusted risk reduction associated with bezafibrate vs. placebo treatment by pre-specified triglyceride group interaction*. P value for interaction of TG group by treatment allocation $=0.11 .{ }^{*}$ Model further adjusted for age, gender, HDL-C, diabetes, past MI, BMI and glucose levels

among patients with hypertriglyceridemia ( $25 \%$ mortality adjusted risk reduction).

Fibrates are used in clinical practice for the past half century mainly due to their ability to decrease TG. All fibrates are peroxisome proliferators-activated receptors $\alpha$ agonists with ability to enhance the oxidation of fatty acids in liver and muscle and reduce the rate of hepatic lipogenesis, thereby reducing secretion of very-low-density lipoprotein TG. Other important effects of fibrates include an increase of HDL level, activity of lipoprotein lipase, the size of LDL particles and a decrease in the apolipoprotein CIII concentration [14, 15].

The beneficial effects of all major fibrates (gemfibrozil, fenofibrate, bezafibrate) on cardiovascular events could be clearly demonstrated only in patients with dyslipidemia (mainly hypertriglyceridemia) or metabolic syndrome. Metabolic syndrome is an important prognostic sign [16]. In patients without these metabolic abnormalities these effects were absent $[9,17-21]$. In a metaanalysis of dyslipidemic subgroups from 5 randomized control trials (RCT) with fibrates totaling 4726 patients, a $35 \%$ relative risk reduction in cardiovascular events was observed compared with a non-significant $6 \%$ reduction in patients without dyslipidemia [22]. Meta-analysis performed in a general population [23] reflecting a blend of effects in patients with and without dyslipidemia $(45,058$ participants) effect of fibrate therapy was reduced, producing only a modest but still significant $10 \%$ RR reduction for major cardiovascular events and a $13 \%$ RR reduction for coronary events. In these circumstances, the main determinant of the overall results of the fibrate's trial is mainly dependent of the number of the included appropriate patients with dyslipidemia and/or metabolic syndrome.

From the modern point of view, patients who fulfilled inclusion criteria of the BIP trial should been treated primary by statins and not by fibrates. In fact, about $50 \%$ of the patients in the BIP trial were presented with high LDL-C and low TG and probably did not need fibrates at all. In 1994 the Scandinavian Simvastatin Survival Study (4S) conclusions became available [24] and statins were administered to an increasing number of patients participating in the BIP trial in direct discordance with its protocol. Because of worse lipids profile of placebo-allocated patients they received statins in significantly greater proportion during the late period of the trial. Consequently, the wide use of non-study statins led to attenuation of the bezafibrate's effect. After the cessation of the BIP trial the rate of use of statins increased substantially in entire study population and eventually was similar in both treatment groups [25].

After publication of the results from the extended phase of the UKPDS trial [26] the concept of "glycemic legacy" was widely discussed. In the 10-year post-trial follow-up, patients with type 2 diabetes originally allocated to intensive hypoglycemic treatment had a significant reduction in the risk of all-cause mortality after the cessation of randomized interventions. These results were obtained although there were no longer differences in HbA1c values between patients originally assigned to conventional or intensive-treatment groups.

To the best of our knowledge, our study is the first which demonstrated in patients with CAD and particularly in patients with hypertriglyceridemia the presence of long term "metabolic memory" for lipids-modified effects of bezafibrate. Our data together with the results from the extended phase of the UKPDS and STENO 2 trials [26-28] provide evidence that the beneficial results of the effective management of cardio-metabolic risk factors could be seen over many years even after the cessation of treatment. Pooled together, these findings support the possible positive role of a "metabolic legacy" for patients with high cardiovascular risk, rather than only a "glycemic legacy" for diabetic patients.

Currently statins are the cornerstone of the treatment and prevention of cardiovascular diseases related to atherosclerosis including CAD [29-32]. Nonetheless, despite the almost universal use of statins in the setting of secondary prevention of CAD, significant residual cardiovascular risk is still present, especially in patients with hypertriglyceridemia and metabolic syndrome [1,33]. The current guidelines recommend considering combination fibrate-statin therapy for patients when statin therapy alone is not adequate to achieve lipid goals [29, 32, 34]. Despite the strong theoretical background, there are only few hard outcomes data regarding combined 
bezafibrate and statin treatment: one small randomized study [35] and number of observational studies [36-38]. In these observations bezafibrate/statin treatment was a safe and was associated with a lower incidence of major cardiovascular events compared with statins alone. Beneficial effects of long-term combination therapy with bezafibrate and ezetimibe in patients with dyslipidemia were also reported [39]. Probably, combined bezafibrate/ statin or bezafibrate/ezetimibe therapy will be more effective in achieving a comprehensive lipid control and residual cardiovascular risk reduction and theoretically might prevent statin-associated new-onset diabetes [40].

\section{Study limitations}

The present study is limited by the post hoc nature of the analysis of the BIP study. It should also be noted that the significant long-term effects of bezafibrate therapy could be observed only after adjustment for important established prognostic predictors including initiation of statins during the double-blind phase of the BIP trial. We do not have information regarding medications or events after the cessation of the BIP trial beyond all-cause mortality nor can we account for changes in medical practice and management guidelines over the long follow-up period. Therefore, further studies are needed to determine the possible long-term mortality benefit of bezafibrate in the current era of universal statin-based secondary prevention in CAD patients.

\section{Conclusions}

Patients treated during the original BIP trial period by bezafibrate experienced a modest but significant $10 \%$ reduction in the adjusted risk of mortality during extended follow-up of 20 years. The long-term benefit of bezafibrate was more prominent among patients with baseline hypertriglyceridemia ( $25 \%$ mortality risk reduction). The present findings suggest that bezafibrate in patients with $C A D$ and hypertriglyceridemia could be associated with a significant long-term mortality reduction that extends far beyond the period of active treatment with the drug.

\section{Additional files}

Additional file 1: Table A. Baseline Clinical and Laboratory Characteristics of the study cohort by original study allocation.

Additional file 2: Table B. Baseline Clinical and Laboratory Characteristics of the study cohort by triglyceride level $\geq$ and $<200 \mathrm{mg} / \mathrm{dl}$.

\section{Abbreviations}

AP: angina pectoris; BMI: body mass index; CHD: coronary heart disease; DM: diabetes mellitus; HDL-C: high-density lipoprotein cholesterol; LDL-C: low-density lipoprotein cholesterol; LLD: lipid lowering drugs; MI: myocardial infarction; TG: triglycerides; BIP: Bezafibrate Infarction Prevention.

\section{Authors' contributions}

YA, RK, IG,EVG, AT, AE,NS,EVF participated in the design of the study and performed the statistical analysis and and helped to draft the manuscript. All authors read and approved the final manuscript.

\section{Author details}

${ }^{1}$ Department of Cardiology, Tel Aviv Medical Center, Affiliated to the Sackler Faculty of Medicine, Tel Aviv University, Tel Aviv, Israel. ${ }^{2}$ Leviev Heart Center, Sheba Medical Center, Tel Aviv, Affiliated to the Sackler Faculty of Medicine, Tel Aviv University, Tel Aviv, Israel. ${ }^{3}$ Cardiovascular Diabetology Research Foundation, Holon, Israel. ${ }^{4}$ The Israeli Association for Cardiovascular Trials, Tel Hashomer, Israel. ${ }^{5}$ Heart Research Follow-up Program, University of Rochester, Rochester, NY, USA.

\section{Competing interests}

The authors declare that they have no competing interests.

Received: 21 November 2015 Accepted: 8 January 2016

Published online: 22 January 2016

\section{References}

1. Schwartz GG, Abt M, Bao W, DeMicco D, Kallend D, Miller M, et al. Fasting triglycerides predict recurrent ischemic events in patients with acute coronary syndrome treated with statins. J Am Coll Cardiol. 2015;65(21):226775. doi:10.1016/j.jacc.2015.03.544.

2. Pollin TI, Damcott CM, Shen H, Ott SH, Shelton J, Horenstein RB, et al A null mutation in human APOC3 confers a favorable plasma lipid profile and apparent cardioprotection. Science. 2008;322(5908):1702-5. doi:10.1126/science.1161524.

3. Jorgensen AB, Frikke-Schmidt R, West AS, Grande P, Nordestgaard BG, Tybjaerg-Hansen A. Genetically elevated non-fasting triglycerides and calculated remnant cholesterol as causal risk factors for myocardial infarction. Eur Heart J. 2013;34(24):1826-33. doi:10.1093/eurheartj/ehs431.

4. Jorgensen AB, Frikke-Schmidt R, Nordestgaard BG, Tybjaerg-Hansen A. Loss-of-function mutations in APOC3 and risk of ischemic vascular disease. N Engl J Med. 2014;371(1):32-41. doi:10.1056/NEJMoa1308027.

5. Crosby J, Peloso GM, Auer PL, Crosslin DR, Stitziel NO, Lange LA, et al. Loss-of-function mutations in APOC3, triglycerides, and coronary disease. N Engl J Med. 2014;371(1):22-31. doi:10.1056/NEJMoa1307095.

6. Tenenbaum A, Klempfner R, Fisman EZ. Hypertriglyceridemia: a too long unfairly neglected major cardiovascular risk factor. Cardiovasc Diabetol. 2014;13:159. doi:10.1186/s12933-014-0159-y.

7. Nordestgaard BG, Varbo A. Triglycerides and cardiovascular disease. Lancet. 2014;384(9943):626-35. doi:10.1016/s0140-6736(14)61177-6.

8. Joshi PH, Martin SS, Blumenthal RS. The remnants of residual risk. J Am Coll Cardiol. 2015;65(21):2276-8. doi:10.1016/j.jacc.2015.03.543.

9. Prevention The Bezafibrate Infarction (BIP) study group. Secondary prevention by raising $\mathrm{HDL}$ cholesterol and reducing triglycerides in patients with coronary artery disease. Circulation. 2000;102(1):21-7.

10. Tenenbaum A, Motro M, Fisman EZ, Tanne D, Boyko V, Behar S. Bezafibrate for the secondary prevention of myocardial infarction in patients with metabolic syndrome. Arch Intern Med. 2005;165(10):1154-60. doi:10.1001/archinte.165.10.1154.

11. Goldbourt U, Brunner D, Behar S, Reicher-Reiss H. Baseline characteristics of patients participating in the Bezafibrate Infarction Prevention (BIP) Study. Eur Heart J. 1998;19(Suppl H):H42-7.

12. Goldbourt U, Behar S, Reicher-Reiss H, Agmon J, Kaplinsky E, Graff E, et al. Rationale and design of a secondary prevention trial of increasing serum high-density lipoprotein cholesterol and reducing triglycerides in patients with clinically manifest atherosclerotic heart disease (the Bezafibrate Infarction Prevention Trial). Am J Cardiol. 1993;71(11):909-15.

13. Lipids and lipoproteins in symptomatic coronary heart disease. Distribution, intercorrelations, and significance for risk classification in 6,700 men and 1,500 women. The Bezafibrate Infarction Prevention (BIP) Study Group, Israel. Circulation. 1992;86(3):839-48.

14. Tenenbaum A, Fisman EZ. Fibrates are an essential part of modern anti-dyslipidemic arsenal: spotlight on atherogenic dyslipidemia and residual risk reduction. Cardiovasc Diabetol. 2012;11:125. doi:10.1186/1475-2840-11-125. 
15. Knopp RH. Drug treatment of lipid disorders. N Engl J Med. 1999;341(7):498-511. doi:10.1056/nejm199908123410707.

16. Arbel Y, Havakuk O, Halkin A, Revivo M, Berliner S, Herz I, et al. Relation of metabolic syndrome with long-term mortality in acute and stable coronary disease. Am J Cardiol. 2015;115(3):283-7. doi:10.1016/j. amjcard.2014.10.037.

17. Ginsberg HN, Elam MB, Lovato LC, Crouse JR 3rd, Leiter LA, Linz P, et al. Effects of combination lipid therapy in type 2 diabetes mellitus. N Engl J Med. 2010;362(17):1563-74. doi:10.1056/NEJMoa1001282.

18. Scott R, O'Brien R, Fulcher G, Pardy C, D'Emden M, Tse D, et al. Effects of fenofibrate treatment on cardiovascular disease risk in 9,795 individuals with type 2 diabetes and various components of the metabolic syndrome: the Fenofibrate Intervention and Event Lowering in Diabetes (FIELD) study. Diabetes Care. 2009;32(3):493-8. doi:10.2337/dc08-1543.

19. Keech A, Simes RJ, Barter P, Best J, Scott R, Taskinen MR, et al. Effects of long-term fenofibrate therapy on cardiovascular events in 9795 people with type 2 diabetes mellitus (the FIELD study): randomised controlled trial. Lancet. 2005;366(9500):1849-61. doi:10.1016/ s0140-6736(05)67667-2.

20. Manninen $\mathrm{V}$, Tenkanen L, Koskinen P, Huttunen JK, Manttari M, Heinonen $\mathrm{OP}$, et al. Joint effects of serum triglyceride and LDL cholesterol and HDL cholesterol concentrations on coronary heart disease risk in the Helsinki Heart Study. Implications for treatment. Circulation. 1992;85(1):37-45.

21. Robins SJ, Collins D, Wittes JT, Papademetriou V, Deedwania PC, Schaefer EJ, et al. Relation of gemfibrozil treatment and lipid levels with major coronary events: VA-HIT: a randomized controlled trial. JAMA. 2001;285(12):1585-91.

22. Sacks FM, Carey VJ, Fruchart JC. Combination lipid therapy in type 2 diabetes. N Engl J Med. 2010;363(7):692-4 (author reply 4-5).

23. Jun M, Foote C, LV J, Neal B, Patel A, Nicholls SJ, et al. Effects of fibrates on cardiovascular outcomes: a systematic review and meta-analysis. Lancet. 2010;375(9729):1875-84. doi:10.1016/s0140-6736(10)60656-3.

24. Scandinavian Simvastatin Survival Study Group. Randomised trial of cholesterol lowering in 4444 patients with coronary heart disease: the Scandinavian Simvastatin Survival Study (4S). Lancet. 1994;344(8934):1383-9

25. Goldenberg I, Benderly M, Goldbourt U. Secondary prevention with bezafibrate therapy for the treatment of dyslipidemia: an extended follow-up of the BIP trial. J Am Coll Cardiol. 2008;51(4):459-65. doi:10.1016/j. jacc.2007.09.048.

26. Holman RR, Paul SK, Bethel MA, Matthews DR, Neil HA. 10-year followup of intensive glucose control in type 2 diabetes. N Engl J Med. 2008;359(15):1577-89. doi:10.1056/NEJMoa0806470.

27. Bianchi C, Del Prato S. Metabolic memory and individual treatment aims in type 2 diabetes-outcome-lessons learned from large clinical trials. Rev Diabet Stud RDS. 2011;8(3):432-40. doi:10.1900/rds.2011.8.432.

28. Gaede $\mathrm{P}$, Lund-Andersen $\mathrm{H}$, Parving HH, Pedersen O. Effect of a multifactorial intervention on mortality in type 2 diabetes. N Engl J Med. 2008;358(6):580-91. doi:10.1056/NEJMoa0706245.

29. National Cholesterol Education Program (NCEP) Expert Panel on Detection, Evaluation, and Treatment of High Blood Cholesterol in Adults (Adult Treatment Panel III). Third Report of the National Cholesterol Education Program (NCEP) Expert Panel on Detection, Evaluation, and Treatment of High Blood Cholesterol in Adults (Adult Treatment Panel III) final report. Circulation. 2002;106(25):3143-421
30. Cannon CP, Steinberg BA, Murphy SA, Mega JL, Braunwald E. Meta-analysis of cardiovascular outcomes trials comparing intensive versus moderate statin therapy. J Am Coll Cardiol. 2006;48(3):438-45. doi:10.1016/j. jacc.2006.04.070.

31. Jukema JW, Cannon CP, de Craen AJ, Westendorp RG, Trompet S. The controversies of statin therapy: weighing the evidence. J Am Coll Cardiol. 2012;60(10):875-81. doi:10.1016/j.jacc.2012.07.007.

32. Stone NJ, Robinson JG, Lichtenstein AH, Bairey Merz CN, Blum CB, Eckel $\mathrm{RH}$, et al. $2013 \mathrm{ACC} / \mathrm{AHA}$ guideline on the treatment of blood cholesterol to reduce atherosclerotic cardiovascular risk in adults: a report of the American College of Cardiology/American Heart Association Task Force on Practice Guidelines. J Am Coll Cardiol. 2014;63(25 Pt B):2889-934. doi:10.1016/j.jacc.2013.11.002.

33. Fruchart JC, Davignon J, Hermans MP, Al-Rubeaan K, Amarenco P, Assmann $G$, et al. Residual macrovascular risk in 2013: what have we learned? Cardiovasc Diabetol. 2014;13:26. doi:10.1186/1475-2840-13-26.

34. Berglund L, Brunzell JD, Goldberg AC, Goldberg IJ, Sacks F, Murad MH, et al. Evaluation and treatment of hypertriglyceridemia: an Endocrine Society clinical practice guideline. J Clin Endocrinol Metab. 2012;97(9):2969-89. doi:10.1210/jc.2011-3213.

35. Madrid-Miller A, Moreno-Ruiz LA, Borrayo-Sanchez G, Almeida-Gutierrez E, Martinez-Gomez DF, Jauregui-Aguilar R. Ipact of bezafibrate treatment in patients with hyperfibrinogenemia and ST-elevation acute myocardial infarction: a randomized clinical trial. Cir Cir. 2010;78(3):229-37.

36. Klempfner R, Goldenberg I, Fisman EZ, Amit U, Haitovich A, Matetzky $S$, et al. Bezafibrate treatment is associated with a reduced rate of re-hospitalization in smokers after acute coronary syndrome. Cardiol J. 2014;21(4):364-9. doi:10.5603/CJ.a2013.0127.

37. Tenenbaum A, Medvedofsky D, Fisman EZ, Bubyr L, Matetzky S, Tanne $D$, et al. Cardiovascular events in patients received combined fibrate/ statin treatment versus statin monotherapy: Acute Coronary Syndrome Israeli Surveys data. PLoS One. 2012;7(4):e35298. doi:10.1371/journal. pone.0035298.

38. Klempfner R, Goldenberg I, Fisman EZ, Matetzky S, Amit U, Shemesh J, et al. Comparison of statin alone versus bezafibrate and statin combination in patients with diabetes mellitus and acute coronary syndrome. Am J Cardiol. 2014;113(1):12-6. doi:10.1016/j.amjcard.2013.08.033.

39. Teramoto T, Abe K, Taneyama T. Safety and efficacy of long-term combination therapy with bezafibrate and ezetimibe in patients with dyslipidemia in the prospective, observational J-COMPATIBLE study. Cardiovasc Diabetol. 2013;6(12):163.

40. Tenenbaum A, Fisman EZ. Balanced pan-PPAR activator bezafibrate in combination with statin: comprehensive lipids control and diabetes prevention? Cardiovasc Diabetol. 2012;11:140. doi:10.1186/1475-2840-11-140.

\section{Submit your next manuscript to BioMed Central and we will help you at every step:}

- We accept pre-submission inquiries

- Our selector tool helps you to find the most relevant journal

- We provide round the clock customer support

- Convenient online submission

- Thorough peer review

- Inclusion in PubMed and all major indexing services

- Maximum visibility for your research

Submit your manuscript at www.biomedcentral.com/submit

(O) BioMed Central 